\title{
National Human Resources Survey of Clinical Neurophysiologists in Canada
}

\author{
K. Ming Chan, G. Bryan Young, Sharon Warren
}

\begin{abstract}
Background: Although electromyography (EMG), electroencephalography (EEG) and evoked potential (EP) studies are common investigation tools for patients with neurologic illnesses, no formal data on the manpower supply in Canada exists. Because of the importance of these on training requirements and future planning, the purpose of this study was to establish a comprehensive profile of the human resources situation in clinical neurophysiological services across Canada. Methods: A questionnaire was sent to all clinical neurophysiologists in Canada. To capture the maximal number of respondents, a total of three rounds of mail out were done. In addition, to obtain accurate demographic data on supporting technologists, a separate survey was also carried out by the Association of Electrophysiological Technologists of Canada. Results: Of the 450 clinical neurophysiologists identified and surveyed, the provincial response rate was $59 \pm 14 \%$ (mean \pm SD). Of these, the vast majority practiced in urban centres. There was substantial regional disparity in different provinces. While the wait time for most EEG and EP laboratories was less than six weeks, the wait time for EMG was substantially longer. With the age of the largest number of practitioners in their sixth decade, projected retirement over the next 15 years was $58 \%$. The demographic distribution of the supporting technologists showed a similar trend. Conclusions: In addition to considerable regional disparity and urban/rural divide, a large percentage of clinical neurophysiologists and supporting technologists planned to retire within the coming decade. To ensure secure and high standard services to Canadians, solutions to fill this void are urgently needed.
\end{abstract}

RÉSUMÉ: Enquête nationale sur les ressources humaines en neurophysiologie clinique au Canada. Contexte : Bien que l'électromyographie (EMG), l'électroencéphalographie (EEG) et l'étude des potentiels évoqués (PE) soient des examens fréquemment utilisés chez les patients atteints de maladies neurologiques, il n'existe pas de données rigoureuses sur la main-d'œuvre dans ce domaine au Canada. Le but de cette étude était d'établir un profil étendu de la situation des ressources humaines dans les services de neurophysiologie clinique au Canada, vu l'importance de ces données pour établir les besoins de formation et de planification. Méthodes : Un questionnaire a été envoyé à tous les neurophysiologistes cliniques du Canada. Trois envois ont été effectués afin de recueillir le plus de réponses possible. De plus, une étude distincte a également été menée par l'Association canadienne des technologues en électrophysiologie afin d'obtenir des données démographiques exactes sur le personnel de soutien technique. Résultats : Le taux de réponse provincial a été de $59 \pm 14 \%$ (moyenne \pm écart type) chez les 450 neurophysiologistes cliniques identifiés sur qui l'enquête a porté. La grande majorité d'entre eux travaillaient dans des centres urbains. Il existait une disparité régionale importante dans certaines provinces. Bien que le temps d'attente soit de moins de 6 semaines pour subir un examen dans les laboratoires d'EEG ou de PE, le temps d'attente pour un EMG était beaucoup plus long. Comme l'âge de la plupart des neurophysiologistes se situe dans la sixième décennie, 58\% ont l'intention de prendre leur retraite d'ici les 15 prochaines années. On observait la même tendance dans la distribution démographique des technologues de soutien. Conclusions : En plus d'avoir constaté une disparité régionale considérable ainsi qu'une disparité urbaine/rurale, un fort pourcentage des neurophysiologistes cliniques et des technologues de soutien ont l'intention de se retirer dans les dix prochaines années. Il est urgent de trouver des solutions pour combler ce vide afin d'assurer aux Canadiens la sécurité des services et des standards élevés.

Can. J. Neurol. Sci. 2009; 36: 321-325

Electromyography (EMG), electroencephalography (EEG) and evoked potential (EP) studies are common investigation tools for patients with neurologic illnesses. Electromyography is used in the diagnosis of diseases affecting peripheral nerve and muscle. For the diagnosis and monitoring of central nervous system diseases such as epilepsy and multiple sclerosis, EEG and EP studies play an important role. The establishment of training requirements and adjudication of clinical competence of those engaged in clinical neurophysiological practice in Canada are overseen by the Canadian Society for Clinical Neuro-
From the Division of Physical Medical \& Rehabilitation (KMC), Faculty of Rehabilitation Medicine (SW), University of Alberta, Edmonton, Alberta; Department of Clinical Neurological Sciences (GBY), University of Western Ontario, London, Ontario, Canada.

Received October 30, 2008. Final Revisions Submitted January 12, 2009 Correspondence to: K. Ming Chan, 513 Heritage Medical Research Centre, University of Alberta, Edmonton, Alberta, T6G 2S2, Canada. 
physiologists (CSCN) - a national body formed by practicing clinical neurophysiologists and research scientists across the country. Through informal discussions at national meetings, the authors (KMC, GBY) discovered that there was a general sense of substantial regional disparities and major urban/rural divide. However, no formal data to support these observations exist. This represents a major void as accurate information is critical to ensure adequate present and future manpower supply, uniformity of qualification standard and technical support for these services. All these have important implications in determining the standard of care delivered to Canadians across the country.

The purpose of this study was to establish a comprehensive profile of the current and projected human resources situation in clinical neurophysiological services across Canada. A major effort was undertaken between 2006 and 2007 to gather data from clinical neurophysiologists in Canada through a questionnaire survey.

\section{Methods}

\section{Identification of clinical neurophysiologists in Canada}

Since a national registry of clinical neurophysiologists in Canada does not exist, much effort was spent in compiling a list that includes all practitioners in the field. This was done through a number of means. First, a current membership list of the CSCN was secured. To obtain contact information on non-members, additional information was extracted from the Canadian Medical Directory. These were confirmed with provincial associations representing neurology, physical medicine and rehabilitation, as well as through provincial medical associations and provincial health departments. Finally, to ensure the accuracy of the compiled names, all provincial lists were further checked and confirmed by experienced clinical neurophysiologists within each province.

\section{Questionnaire}

An initial draft of the questionnaire was designed by the investigators. KMC and GBY are experienced clinical neurophysiologists and SW is a clinical epidemiologist with expertise in questionnaire design. To test the content validity, the initial draft was tested on a subset of clinical neurophysiologists across the country. It was also sent to a number of clinical epidemiologists with expertise in questionnaire design. Based on the results and the feedback, the questionnaire was refined, followed by a second round of testing before settling on the final version.

Once the final version was established, a total of three rounds of mailing were done between 2006 and 2007. They were administered by the Canadian Neurological Sciences Federation office in Calgary. Non-respondents were tracked and reminders were sent. To preserve confidentiality and anonymity of the respondents, all three investigators were blinded to the personal identification information of the respondents. This step was taken to encourage maximum disclosure of information and to reassure that there would be not incrimination or personal repercussions based on their response.

All clinical neurophysiologists were asked to fill out a questionnaire on their demographics, qualifications, practice locations, practice pattern, perceived most important priorities and planned retirement age. In addition, laboratory directors were also asked to provide information on wait time and technologist support. Because some directors did not have accurate demographic data of the technologists working in their laboratories, to further elaborate the reported information, a separate survey was also done independently by the Association of Electromyography Technologists of Canada on their own members in mid 2007.

\section{RESULTS}

\section{Ratio of manpower supply in different provinces}

Through the sources described above, we identified a total of 450 clinical neurophysiologists currently practicing in Canada. To compute the ratio of manpower supply, this is further broken down by province. Figures for provincial populations were obtained from data supplied by Statistics Canada. The average number of clinical neurophysiologists per capita in Canada was $1.34 \pm 0.57 / 100,000($ mean $\pm S D)$. However, as shown in Table 1, there are wide differences in the number of clinical neurophysiologists per capita ratio, from a low of $0.61 / 100,000$ in Quebec to 2.14/100,000 in Prince Edward Island.

\section{Response rates}

The overall response rate was reasonably high at $59 \%$ with a range of 40 to $79 \%$ (Figure 1).

The vast majority of respondents were specialists in three disciplines: adult neurology $(60 \%)$, pediatric neurology $(8 \%)$ and physical medicine and rehabilitation $(26 \%)$. The ratio between women (37\%) and men (63\%) was approximately 1 to 2 . Eighty percent of respondents practiced in urban centres, defined as cities with a population of greater than 100,000. Among the respondents, $62 \%$ were members of the $\mathrm{CSCN}$ and had passed the national diploma examination.

\section{Age distributions of the respondents}

The largest number of practitioners was in the sixth decade at $33 \%$, followed by those in the fifth decade (28\%). Together, these two age groups represent over $60 \%$ of all respondents (Figure 2). Of particular note is that the percentage of younger

Table 1: Ratio of clinical neurophysiologist supply to the population in different provinces in Canada

\begin{tabular}{llll}
\hline & Population & Practitioners & Ratio per 100.000 \\
\cline { 2 - 4 } Alberta & $3.38 \mathrm{M}$ & 44 & 1.30 \\
BC & $4.31 \mathrm{M}$ & 40 & 0.93 \\
Manitoba & $1.18 \mathrm{M}$ & 9 & 0.76 \\
New Brunswick & $0.75 \mathrm{M}$ & 14 & 1.87 \\
Newfoundland & $0.51 \mathrm{M}$ & 6 & 1.18 \\
Nova Scotia & $0.93 \mathrm{M}$ & 18 & 1.94 \\
Ontario & $12.69 \mathrm{M}$ & 2.39 & 1.88 \\
PEI & $0.14 \mathrm{M}$ & 3 & 2.14 \\
Quebee & $7.65 \mathrm{M}$ & 47 & 0.61 \\
Saskatchewan & $0.99 \mathrm{M}$ & 8 & 0.81 \\
\hline
\end{tabular}




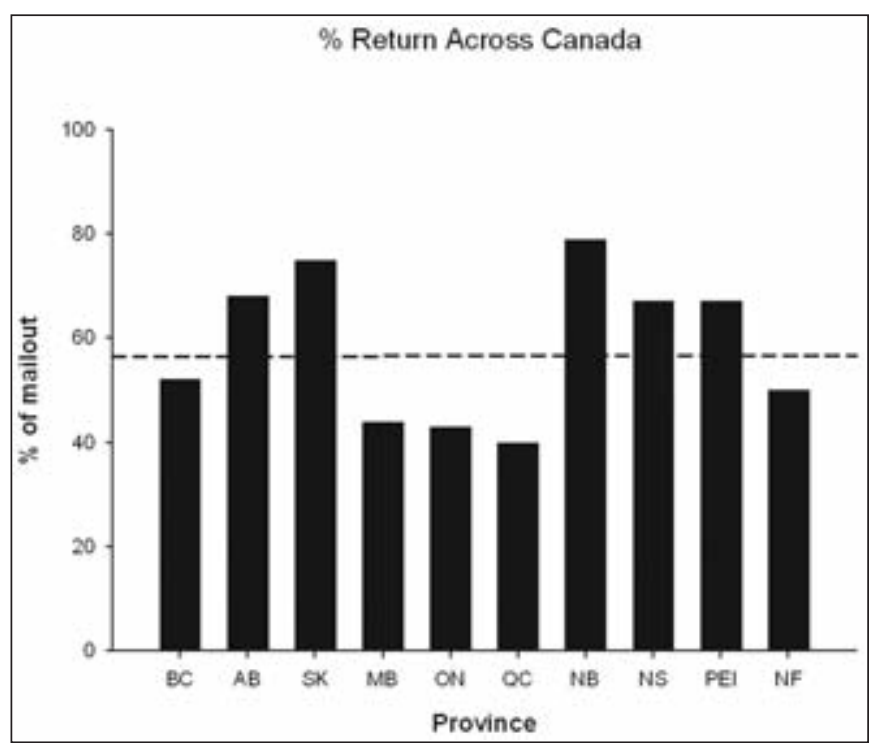

Figure 1: Responding rates in different provinces across Canada. The horizontal dash line represents the mean return rate.

practitioners in the fourth decade was substantially lower at $19 \%$. The implications of this trend will be discussed in detail in the next section.

When asked about intended age of retirement, most respondents indicated that they would stop work around the age of 65 years. This response is in keeping with the age distribution of the respondents. Of the ten respondents in this survey who were over the age of 70 , all but one had already retired. Using the intended retirement age of 65 , we calculated the remaining years of service for each respondent. With that projection, the percentage of potential retirement within the next 15 years will be about $58 \%$ (Figure 3).

\section{Wait time}

While the reported wait time in most EP and EEG laboratories was less than six weeks, the wait time for EMG studies was substantially longer (Figure 4). In over $30 \%$ of laboratories, the wait time was more than ten weeks. When factoring in the additional time required for the prerequisite clinical consultation, the total wait time is even more onerous.

\section{Support staff}

Technologists are an essential and integral part of clinical neurophysiologic services. This is particularly critical in EEG and EP studies where the time demand of individual tests can be substantial. Therefore, the presence and continual supply of technologists have a major impact on the viability of many laboratories.

Like clinical neurophysiologists, demographics of the supporting electrophysiological technology staff showed a similar trend (Figure 5). There were a total of 134 technologists

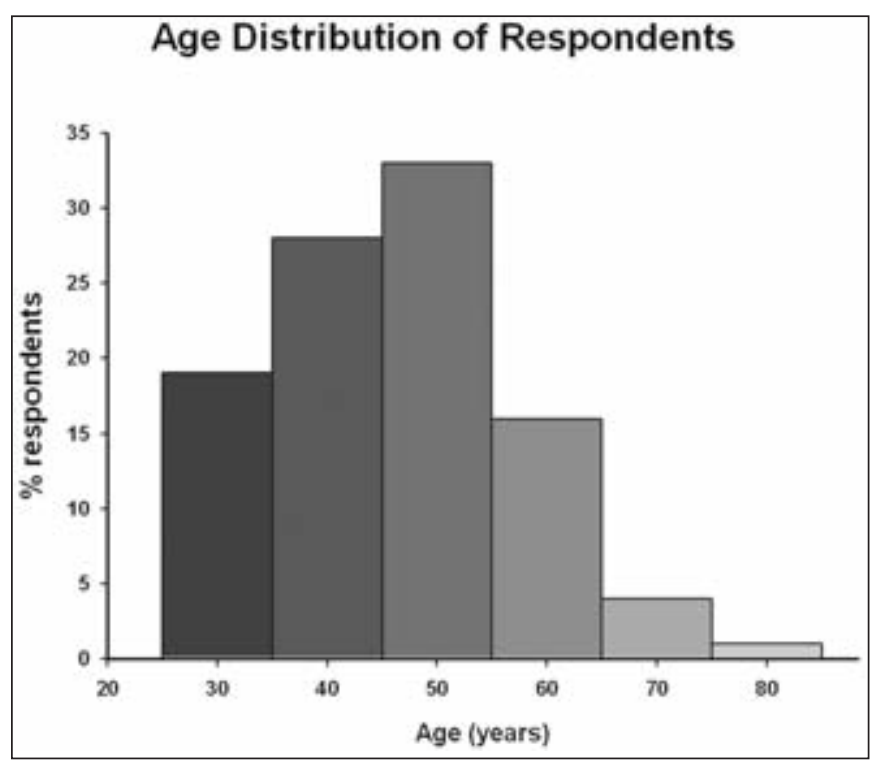

Figure 2: Age distribution of respondents.

in the country. The percentage of technologists doing EMG was $51 \%$, EEG at $29 \%$ and EP at $18 \%$.

\section{The most important priorities}

From a list of seven potential areas of improvements, respondents were asked to rank the most important three. Of these, the five highest priority areas identified were increasing remuneration for clinical neurophysiological testing in provincial fee schedules, putting in place quality control program

Table 2: Priority ranking by the respondents. The top three priorities were fee schedule, quality control program and continuing education for the technologists

\section{\# of Respondents}

Fee schedule

Quality control program to ensure labs meeting minimal standards

Continuing education for techs

Subsidize training for techs

Fellowship

Residency slots

Subsidy for remote region 


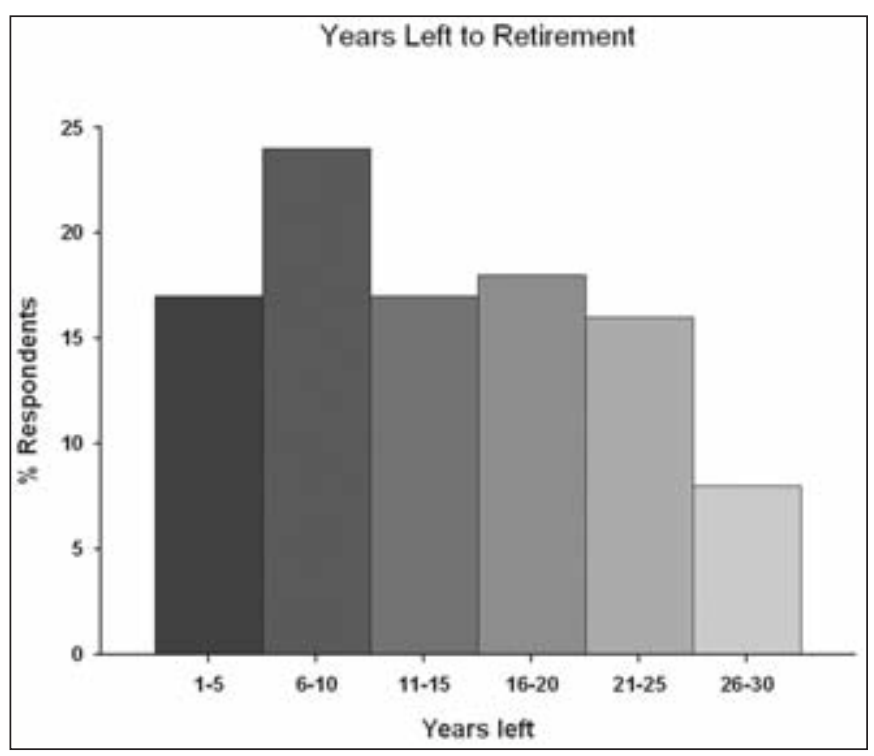

Figure 3: Projected rate of retirement.

to ensure minimal standards, training and continuing education for technologists and clinical fellows (Table 2).

\section{Discussion}

Although many in the field have suspected imbalances in clinical neurophysiological services across Canada for some time, this is the first formal nationwide survey on the manpower supply. With an average of nearly $60 \%$, the response rate is relatively high for this type of questionnaire study and therefore the likelihood of the results being representative of the whole sample is reasonably high.
With graying of the population in Canada and retirement of baby boomers, manpower supply shortage is anticipated in many medical specialties. ${ }^{1-3}$ This is perhaps particularly critical for EMG, EEG and EP services because the average number of 1.39 clinical neurophysiologists available to serve 100,000 Canadians is likely an unduly optimistic estimation. Reason being that the vast majority of practitioners also have other clinical responsibilities. Most of them only do EMG, EEG and EP studies on a part time basis. Indeed, the shortage of human resources is reflected by the long wait time, especially for EMG studies where over $30 \%$ of patients had to wait ten weeks or more. The undue delay in confirmation of diagnosis could carry heavy socioeconomic cost and have severe personal repercussion. For example, those with suspected epileptic seizures needing EEG studies would in the meantime not be able to drive or to return to work while those with peripheral nerve trauma requiring EMG confirmation, with undue delay, may miss the critical time window for surgical intervention. This imbalance will likely be further exacerbated in the coming years. With a projected retirement age of 65 , almost $60 \%$ of the current practitioners plan on retiring within the next 15 years. Even with a more optimistic assumption of retirement at the age of 70 , nearly one third $(32 \%)$ of the current practitioners will still be lost. Given the relatively low number of younger clinical neurophysiologists in Canada, the number for replacement will likely be inadequate.

The survey data also confirms marked disparity in geographic manpower distribution in different regions of Canada. This ranges from a low of $0.61 / 100,000$ in Quebec to 2.14/100,000 in Prince Edward Island. One potential limitation of this data is the lack of a centralized registry that contains all clinical neurophysiologists in Canada. However, by going through the steps of collating multiple sources that included the CSCN membership list, the Canadian Medical Directory, provincial billing information and further cross checking and confirmation by representatives within each province, we are reasonably

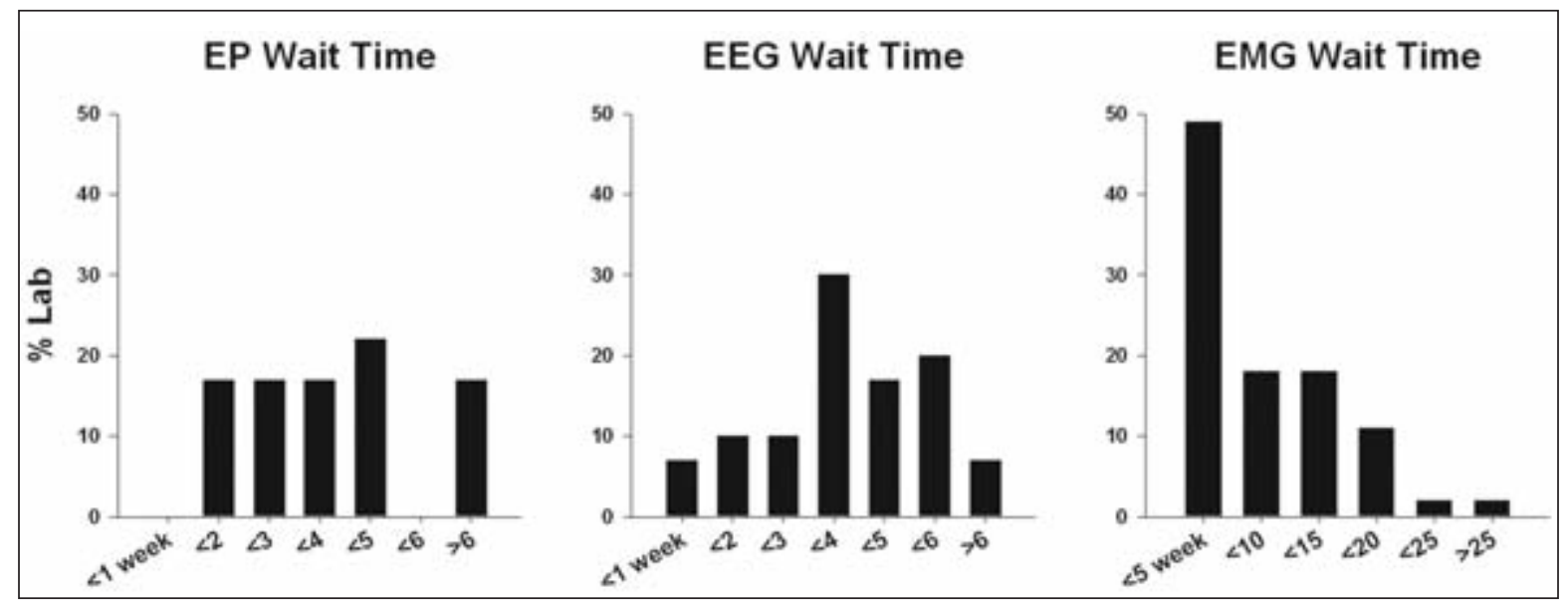

Figure 4: Wait time for EP, EEG and EMG studies. Of these, the wait time for EMG studies was particularly long, with over 30\% of the laboratories taking longer than ten weeks. 


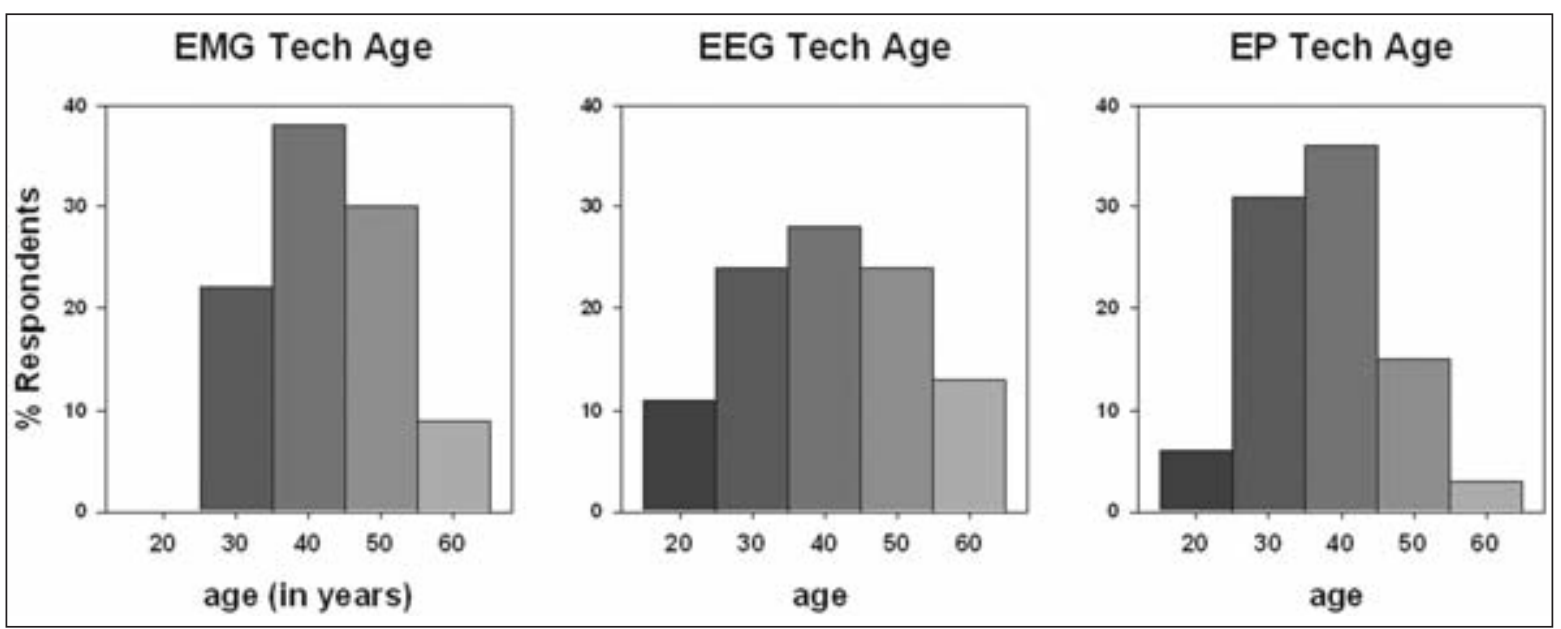

Figure 5: Age distribution of the supporting technologists.

confident about the accuracy of these figures. Perhaps equally striking are differences in the urban/rural divide with the vast majority of practitioners (80\%) working in major urban centres with populations greater than 100,000. Based on figures from Statistics Canada, $71 \%$ of Canadians reside in major urban centres ${ }^{4}$ However, because of regional variations there are likely to be substantial imbalances in geographic accessibility to clinical neurophysiological services. For example, in the Western Canadian provinces, almost all clinical neurophysiologists are concentrated in metropolitan centres. Consequently, it is not uncommon to find many patients having to spend hours traveling to centres where clinical neurophysiological tests can be performed.

Technologists play an important and sometimes indispensable role in clinical neurophysiological services especially in the EEG and EP laboratories. In most instances, those tests are done by technologists and interpreted by physicians. The projected shortage in manpower support among technologists mirrors that of the clinical neurophysiologists. At present, there are only four training programs for clinical electrophysiological technologists in Canada. However, each program only produces a small number of graduates each year. Because of the critical shortage of training positions, many laboratories end up training a small number of technologists to meet their own needs. This is often a laborious, time consuming process that lacks uniformity of training standards.

Part of the solution to head off the course of future decline in manpower supply in clinical electrophysiological services may lie with the key recommendations made by the respondents. Among these, increases in the level of remuneration for clinical neurophysiological testing in provincial fee schedules and the number of training spots for technologists and clinical fellows figure prominently. The last point is particularly challenging in the current system as formal funding mechanisms for clinical fellowship do not exist in most Canadian training centres.

\section{ACKNOWLEDGEMENTS}

Financial and secretarial support for this study was generously provided by the Canadian Neurological Sciences Federation. We thank all the respondents who gave us their valuable time and input and to the Association of Electromyography Technologists of Canada for carrying out an independent member survey. Shelley Martin at the Canadian Medical Association provided valuable suggestions on questionnaire design.

\section{REFERENCES}

1. Bailey P, Warren S, Buske L. Highlights of the 2002 Canadian Neurological Society (CNS) manpower survey. Can J Neurol Sci. 2005; 32(4): 425-32.

2. Keene DL, Humphreys P. Inventory of pediatric neurology "manpower" in Canada. Can J Neurol Sci. 2005; 32(3): 306-10.

3. Bellan L, Buske L. Ophthalmology human resource projections: are we heading for a crisis in the next 15 years? Can J Ophthalmol. 2007; 42(1): 34-38.

4. Statistics Canada. Structure and change in Canada's rural femography: an update to 2006 with provincial detail. Available from: http://www.statcan.gc.ca/pub/21-601-m/21-601m2008090 -eng.pdf. [cited 2008 November 4]. 